\title{
Computational Results for the KTH-NASA Wind-Tunnel Model Used for Acquisition of Transonic Nonlinear Aeroelastic Data
}

\author{
Walter A. Silva, ${ }^{*}$ Pawel Chwalowski, ${ }^{\dagger}$ Carol D. Wieseman ${ }^{\ddagger}$ \\ NASA Langley Research Center, Hampton, Virginia \\ David Eller, ${ }^{\S}$ Ulf Ringertz $₫$ \\ Kungliga Tekniska Högskolan, or Royal Institute of Technology, Stockholm, Sweden
}

\begin{abstract}
A status report is provided on the collaboration between the Royal Institute of Technology (KTH) in Sweden and the NASA Langley Research Center regarding the aeroelastic analyses of a full-span fighter configuration wind-tunnel model. This wind-tunnel model was tested in the Transonic Dynamics Tunnel (TDT) in the summer of 2016. Large amounts of data were acquired including steady/unsteady pressures, accelerations, strains, and measured dynamic deformations. The aeroelastic analyses presented include linear aeroelastic analyses, CFD steady analyses, and analyses using CFD-based reduced-order models (ROMs).
\end{abstract}

\section{Introduction}

There is significant interest within the aerospace community in being able to model, analyze, and predict nonlinear aeroelastic limit cycle oscillations (LCOs). Although there is a significant amount of research being performed across several organizations in this area, a major limitation to this research is the availability of high-quality, transonic LCO data. ${ }^{1-12}$

This paper presents the status of a collaborative effort between the Royal Institute of Technology (KTH) and the NASA Langley Research Center to acquire a high-quality LCO database on a full-span fighter configuration. The configuration selected will be discussed first, followed by a description of the computational aeroelastic analyses performed to date.

\section{Wind-Tunnel Model Configuration}

In 1985 and 1986, two wind-tunnel models of the Saab JAS 39 Gripen were designed, built, and tested in the NASA Transonic Dynamics Tunnel (TDT) for flutter clearance. One model, referred to as the stability model, was designed to be stiff, but incorporated proper scaling of both the mass and geometry. The other model, referred to as the flutter model, was also designed for proper scaling of structural dynamics, and was used for flutter testing with various external stores attached.

For the current collaboration, a single generic fighter flutter-model version of these earlier models was selected. The new model, shown in Figure 1, has a similar outer mold line (OML) to the Gripen, but it has been modified to provide a more generic fighter configuration. Specifically, the air intakes were removed from the fuselage and the wing received an aspect ratio increase and a leading-edge sweep reduction. Details regarding the design, fabrication, and instrumentation of the wind-tunnel model can be found in the references. ${ }^{13}$ Figure 2 shows the wind-tunnel model installed in the TDT.

\footnotetext{
*Senior Research Scientist, Aeroelasticity Branch, AIAA Associate Fellow.

$\dagger$ Aerospace Engineer, Aeroelasticity Branch, AIAA Senior Member.

${ }^{\ddagger}$ Aerospace Engineer, Aeroelasticity Branch, AIAA Associate Fellow.

$\S$ Professor, Department of Aeronautical and Vehicle Engineering, AIAA Member.

I Professor, Department of Aeronautical and Vehicle Engineering, AIAA Member.
} 


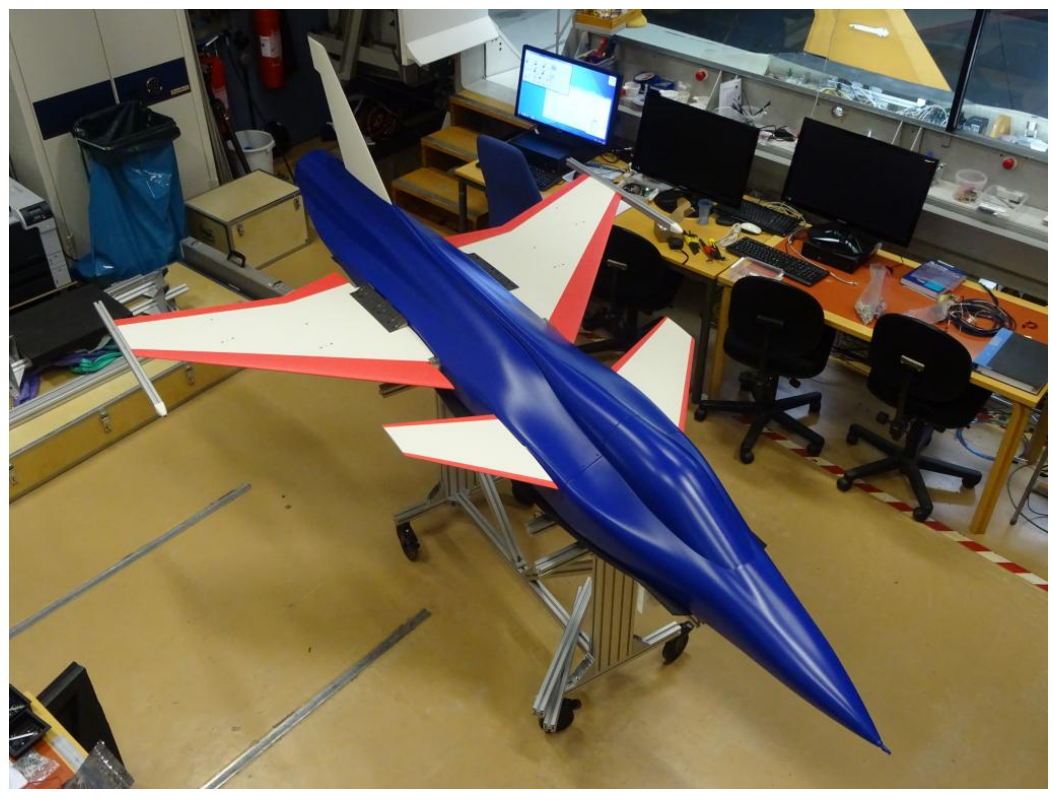

Figure 1. The generic fighter aeroelastic wind-tunnel model tested in summer of 2016 .

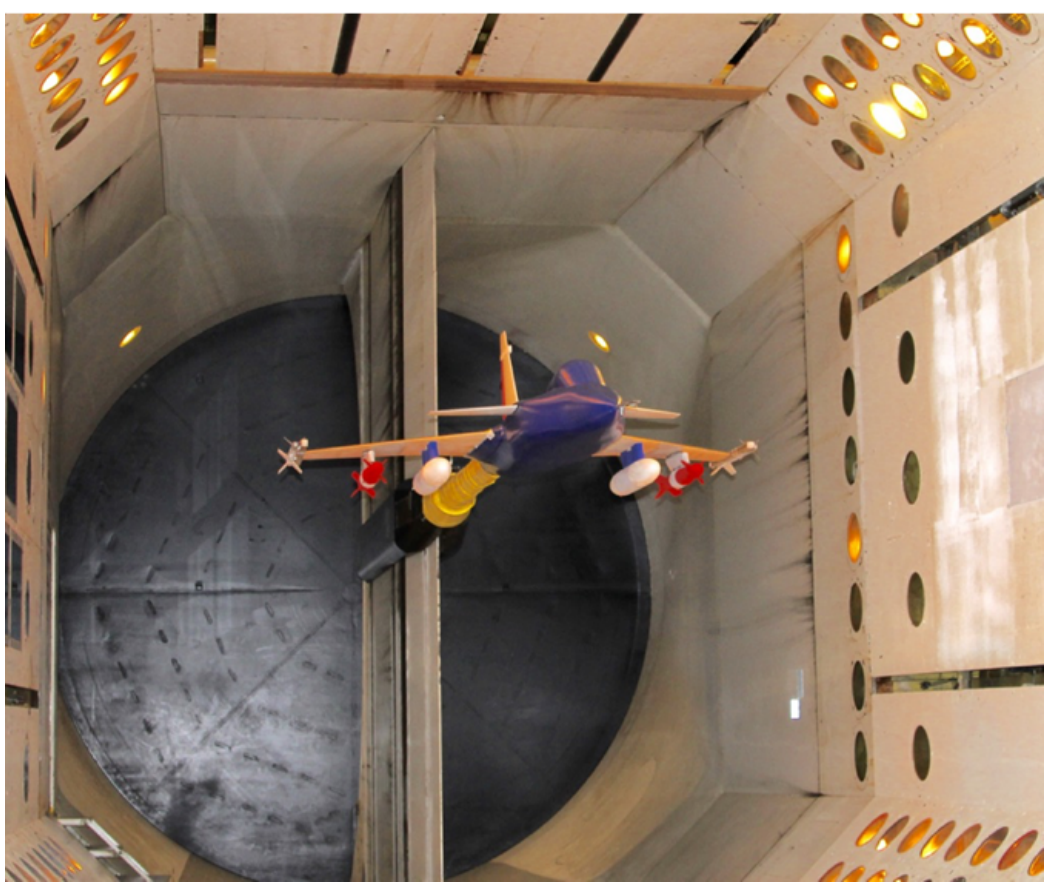

Figure 2. The generic fighter aeroelastic wind-tunnel model installed in the TDT. 


\section{Transonic Dynamics Tunnel}

The NASA Langley Transonic Dynamics Tunnel (TDT) is a unique national facility dedicated to identifying, understanding, and solving relevant aeroelastic problems. The TDT is a closed-circuit, continuous-flow, variable-pressure, wind tunnel with a 16 -foot square test section with cropped corners (Figure 3). The tunnel uses either air or a heavy gas as the test medium and can operate at stagnation pressures from near vacuum to atmospheric, has a Mach number range from near zero to 1.2 and is capable of maximum Reynolds numbers of about 3 million per foot in air and 10 million per foot in heavy gas. Prior to 1998, the TDT used dichlorodifluoromethane, R-12, as the aerodynamic test medium. The TDT now uses 1,1,1,2tetrafluoroethane, R-134a, as the test medium. ${ }^{14,15}$ The TDT is specially configured for flutter testing, with excellent model visibility from the control room and a rapid tunnel shutdown capability for model safety (bypass valves). Model mount systems include a sidewall turntable for semispan models, a variety of stings for full-span models, and a cable-mount system for "flying" models. The TDT also offers an airstream oscillation system for gust studies as well as digital controllers and supporting systems for active controls testing. Testing in heavy gas has important advantages over testing in air: improved model to full-scale similitude (which results in cheaper, heavier models with lower model elastic mode frequencies), higher Reynolds numbers, and reduced tunnel power requirements. These capabilities make the TDT the best-suited facility in the world for flutter testing large, full-span, aeroelastically-scaled models at transonic speeds.

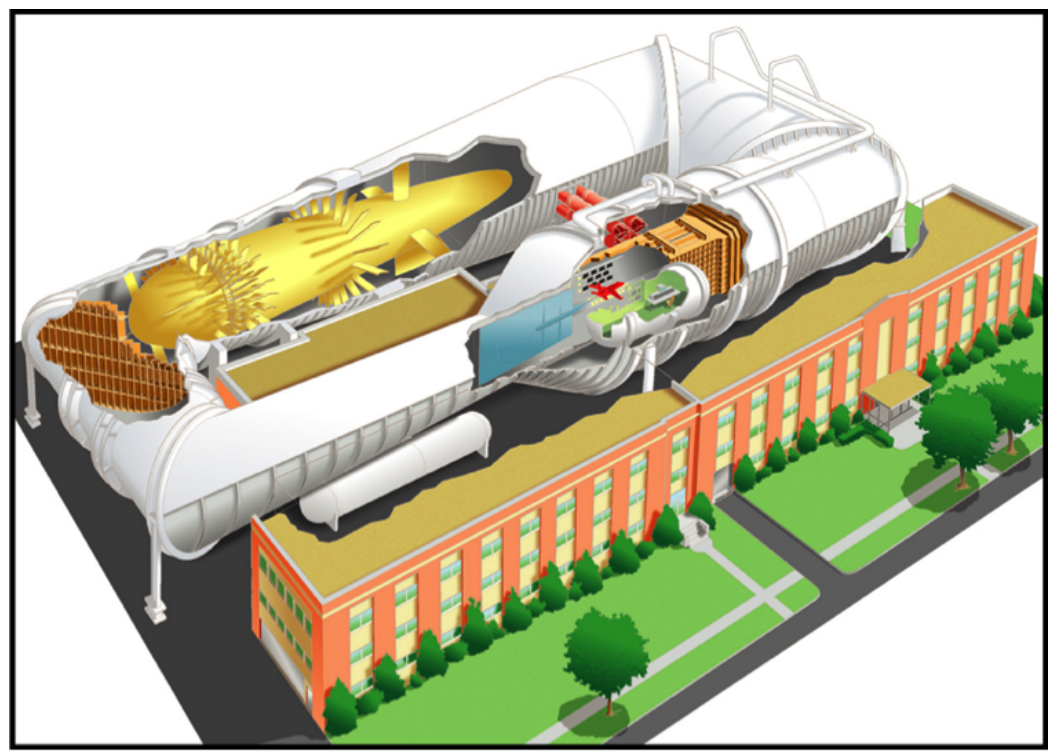

Figure 3. The NASA Transonic Dynamics Tunnel (TDT).

\section{Computational Models}

The computational suite developed for this new wind-tunnel model includes a finite element model (FEM), linear aeroelastic analyses models, and CFD grids/analyses. The FEM was initially developed at KTH, but was continuously updated as the wind-tunnel model hardware was fabricated and evaluated. To date, the FEM has been used to compute loads on the main components and to generate the normal modes for subsequent aeroelastic analyses.

\section{Validation of the Wing Stiffness Model}

The wing design is based on a sandwich structural concept featuring fiberglass reinforced epoxy wing skins over a foam core. There is also an internal fiberglass epoxy support frame for localized forces at wing pylon stations and wing root attachments. The internal frame is localized in the mid plane of the wing to minimize the contribution to overall wing stiffness while ensuring significant strength for high local forces when heavy external stores are attached to the wing. 
The finite element model of the aircraft, shown in Figure 4, was developed for standard linear-elastic finite element analysis using NASTRAN. ${ }^{16}$ In Figure 4, the maximum computed shear values for the design Mach number are presented.

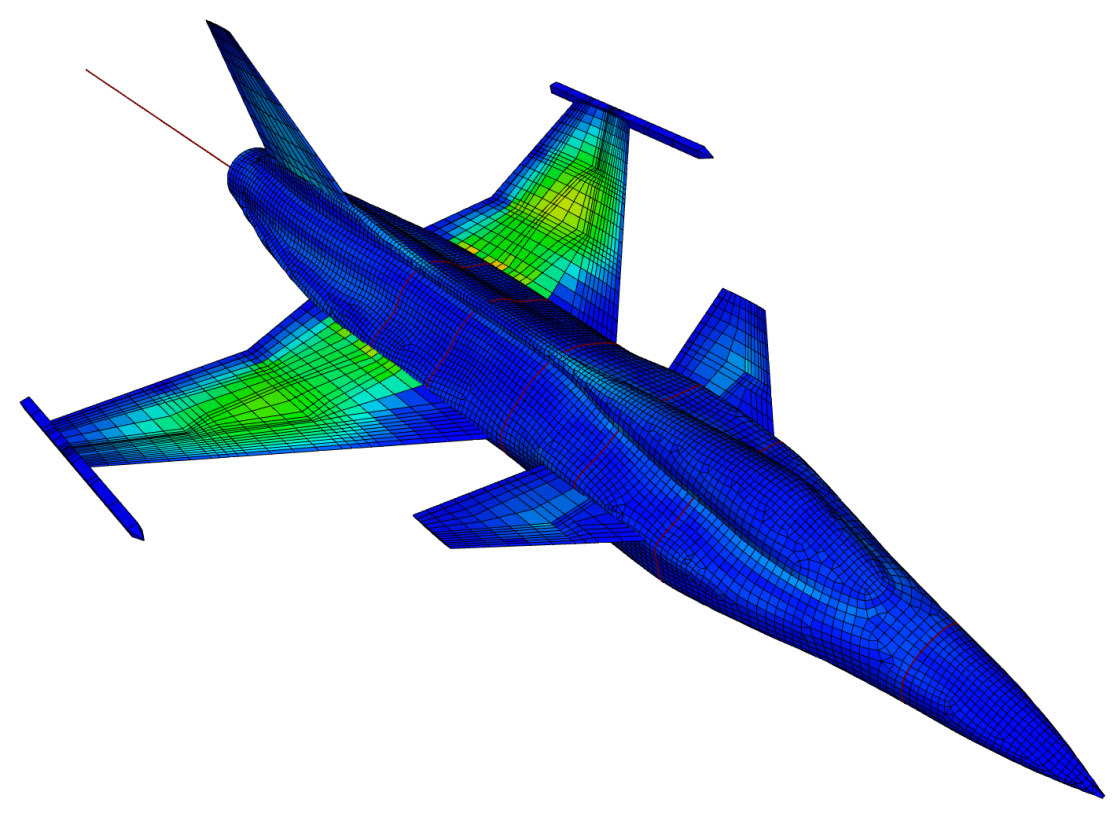

Figure 4. Finite element model of the aircraft on sting mount displaying the maximum computed shear values.

The foam core material is modeled using CHEXA solid elements while wing skins and internal (midplane) plate, and reinforcements are modeled using CQUAD4 shell elements. There are 15,718 total grid points and 17,913 total elements in the FE model. Material properties for the composite laminates where derived by coupon testing of component specimens in a static testing machine as described in Passalacqua. ${ }^{17}$ The remaining material properties were obtained from supplier data sheets of the materials used.

In order to verify the accuracy of the wing finite element model, a full-scale stiffness test is performed using the setup shown in Figure 5. Optical markers are attached to the wing hard points as shown in the Figure. The marker positions are recorded by an optical measurement system ${ }^{18}$ using four motion capture cameras. The system is able to resolve displacements less than $0.1 \mathrm{~mm}$.

The system records the position of each marker in three dimensions with a data rate up to $1 \mathrm{kHz}$. For a static test such as this, the data rate is reduced to $60 \mathrm{~Hz}$ to limit the size of the data files generated. The external loads are applied using dead weights in increments of approximately $2 \mathrm{~kg}$. The weights are removed using the same increment to record the displacements for a full load cycle. Each load level is maintained for approximately 20 seconds, and the average position of each marker is used for the displacement estimate. The load is applied to the same hard point locations as used to attach the optical markers. This way a full matrix of flexibilities is measured. The results obtained for the right wing tip markers and the markers at the outer under-wing pylon station are shown in Figure 6.

The experimental displacement measurements are shown as ' + ' markers and the finite element model displacement results as a solid line. The measured displacement versus load response is close to a linear function.

The flexibility matrices are defined to be $8 \times 8$ using the vertical displacement measurements of the two wing tip markers, the three markers at the outer under-wing pylon station, and the three markers at the inner wing pylon station. The experimentally obtained flexibilities are obtained using a linear least-squares fit of the load versus deflection data as shown in Figure 6. The matrix of flexibilities from the finite element 


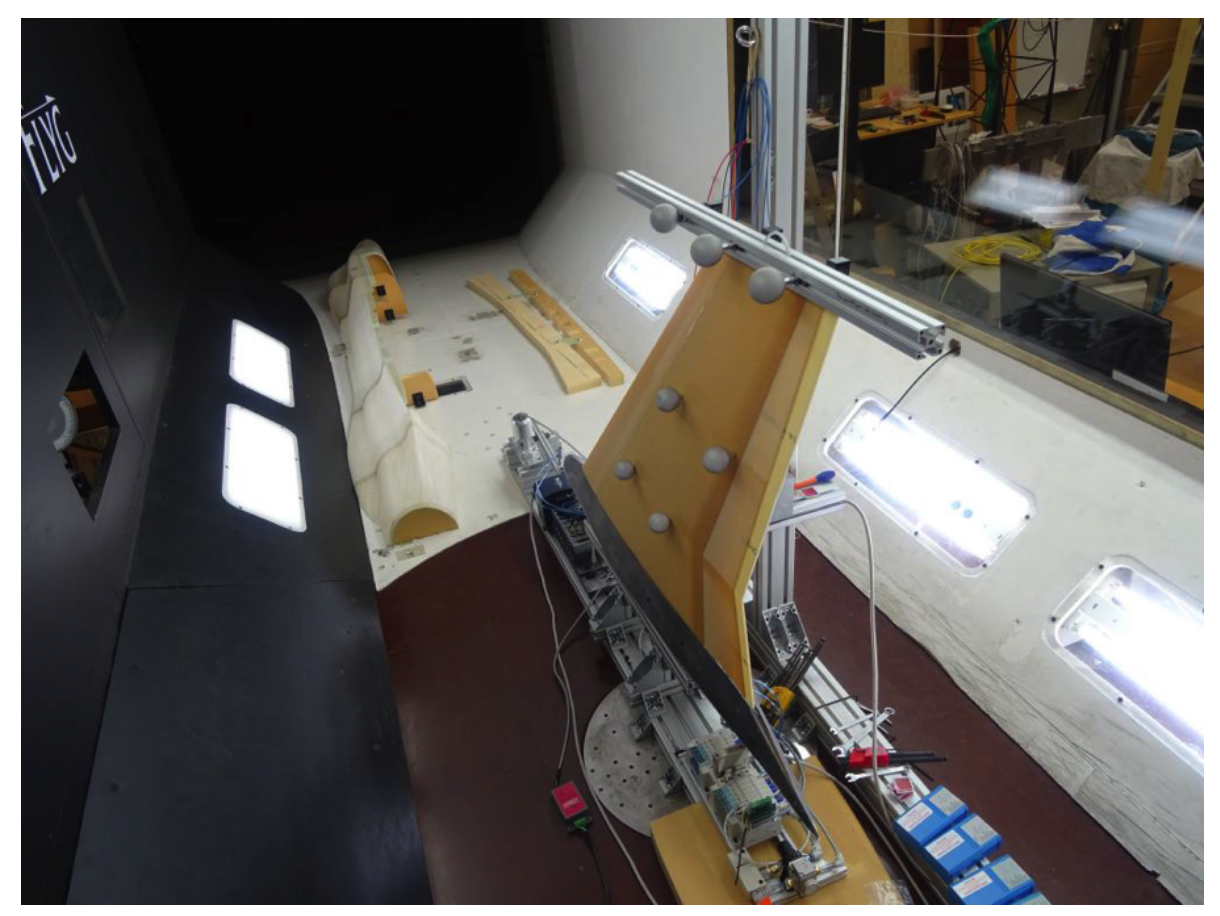

Figure 5. Full-scale stiffness test to improve the accuracy of the FEM.

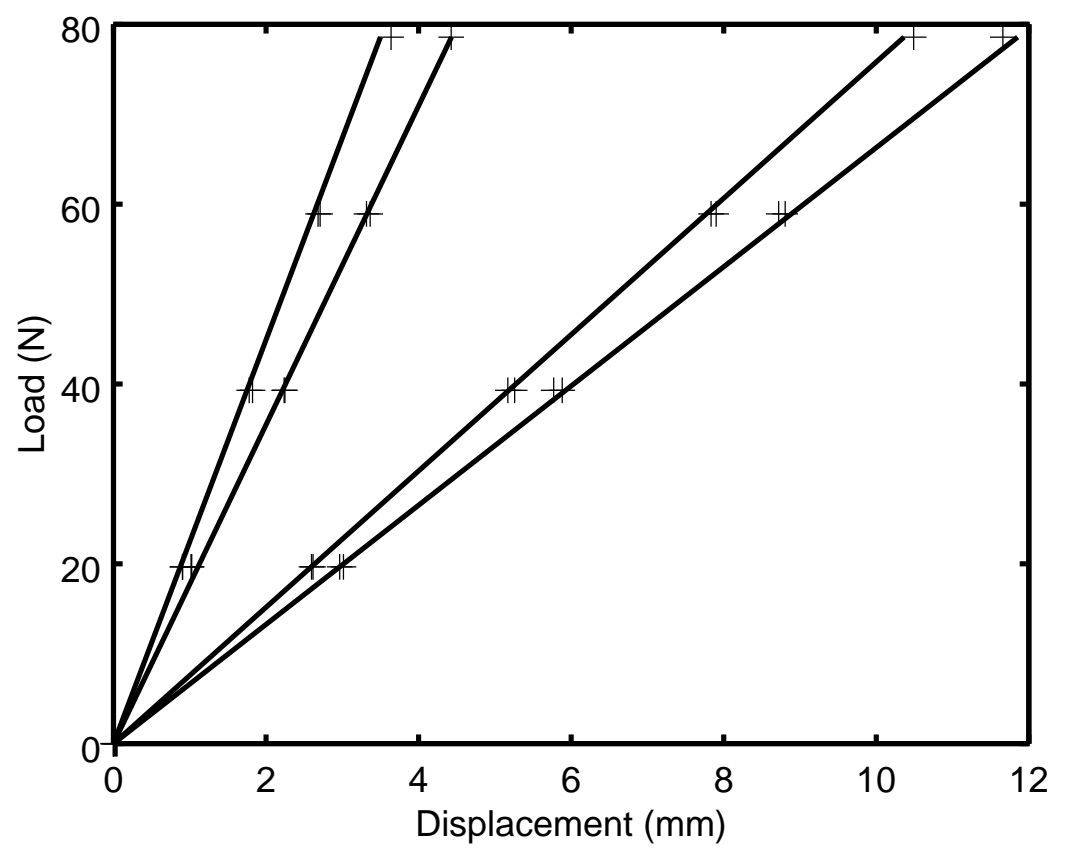

Figure 6. Outer wing marker displacement measurements and finite element model displacement results. 
model is derived by applying unit point loads to the nodes at wing hard points with one separate load case for each hard point.

The finite element model assumes that both wings have identical properties, but the flexibilities of both wings are experimentally recorded in the matrices for the left wing and for the right wing. To compare the flexibility of the two wings with the finite element model, non-dimensional matrix norm quantities are evaluated as shown in Table 1.

\begin{tabular}{lcc} 
Note & Matrix expression & Result \\
\hline Left symmetry & $\|-\| /\|\|$ & 0.014 \\
Right symmetry & $\|-\| /\|\|$ & 0.011 \\
Difference & $\|-\| /\left(\frac{1}{2}\|+\|\right)$ & 0.020 \\
Right vs FEM & $\left\|\frac{1}{2}(+)-\right\| /\|\|$ & 0.039758 \\
Left vs FEM & $\left\|\frac{1}{2}(+)-\right\| /\|\|$ & 0.030674 \\
Average vs FEM & $\left\|\frac{1}{4}(+++)-\right\| /\|\|$ & 0.034568
\end{tabular}

Table 1. Comparison of flexibility matrices.

There is a small difference between the two wings, and the experimentally obtained matrices are not quite symmetric. The overall difference in flexibility between the finite element model and the experimental results is about 3-4\%. Tuning of material properties may reduce the difference between experimental results and the finite element model. This is important information with regards to subsequent modal and aeroelastic analyses.

\section{V.A. Linear Aeroelastic Analyses}

A finite element model (FEM) of the wind-tunnel model was developed by the KTH and was continuously updated during model fabrication and testing. Stiffness and ground vibration tests were performed and provided additional validation data for the FEM. The FEM was then used to generate a normal modes solution. Presented in Figure 7 is a planform view of the FEM of the KTH aeroelastic wind-tunnel model that includes the wind-tunnel sting mount. Presented in Figure 8 is a planform view of the FEM along with the aerodynamic paneling used in linear aeroelastic analyses.

There were three configurations that were tested: the first configuration was the wings with tip stores only; the second configuration was the wings with tip and wing stores; and the third configuration was the wings with tip and wing stores plus $.20 \mathrm{~kg}$ masses added to the tip stores. The first two configurations exhibit no flutter within the TDT test envelope, as anticipated by preliminary analyses. The third configuration exhibit three flutter instabilities at transonic conditions, with the third flutter point resulting in damage to the wing tips.

The first 20 modes of the third configuration range in frequency from 6.75 to $88.46 \mathrm{~Hz}$ with the first mode being a sting mode. Of particular interest are modes 7 and 8 that are very close in frequency but mode 7 is anti-symmetric while mode 8 is symmetric. These two modes are presented in Figure 9 and Figure 10. These modes exist, in part, due to the asymmetry between the left and right wings identified during stiffness testing of the wind-tunnel model. 


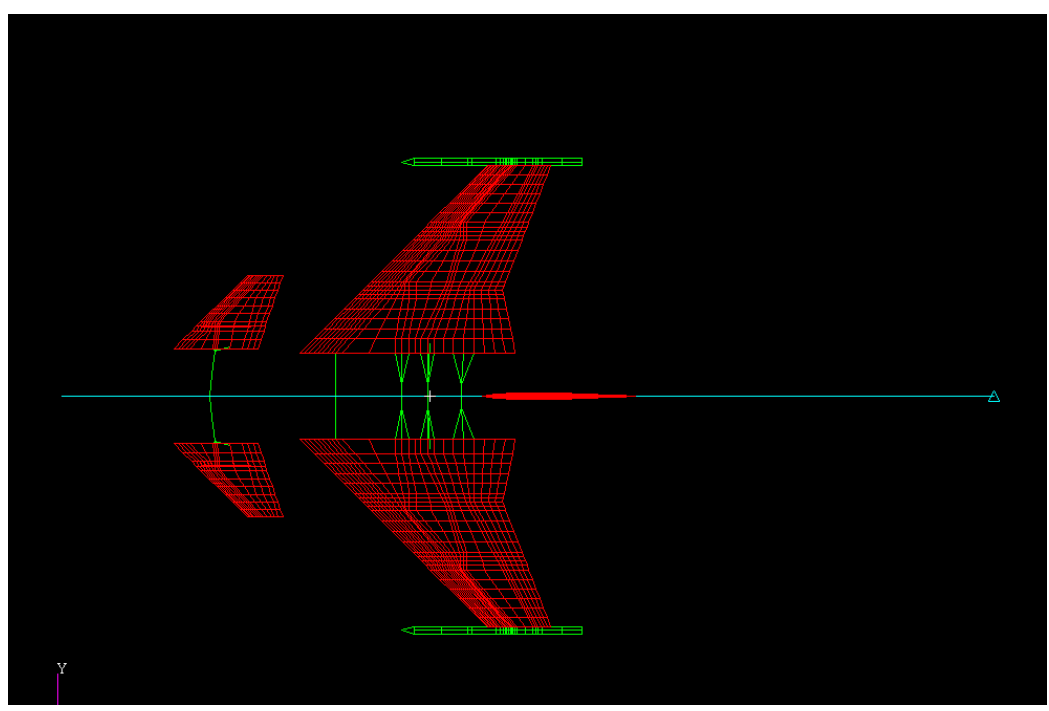

Figure 7. Planform view of the FEM of the KTH aeroelastic wind-tunnel model.

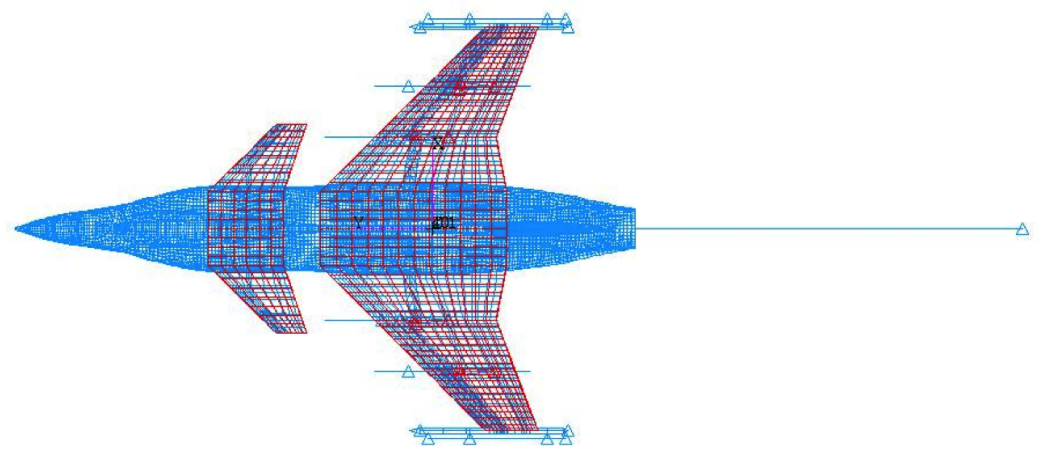

Figure 8. Planform view of the FEM of the KTH aeroelastic wind-tunnel model with the aerodynamic paneling superimposed for use in linear aeroelastic analyses. 
Patran 2014.1 64-Bit 25-May-16 17:05:2

Fringe: SC3 Structure, Al:Mode 7: Freq, = 16.767, Eigenvectors, Transiational, Magnitude. (NON-LAYERED)

Deform: SC3 Structure, A1:Mode 7 : Freq = 16.767, Eigenvectors, Translational.

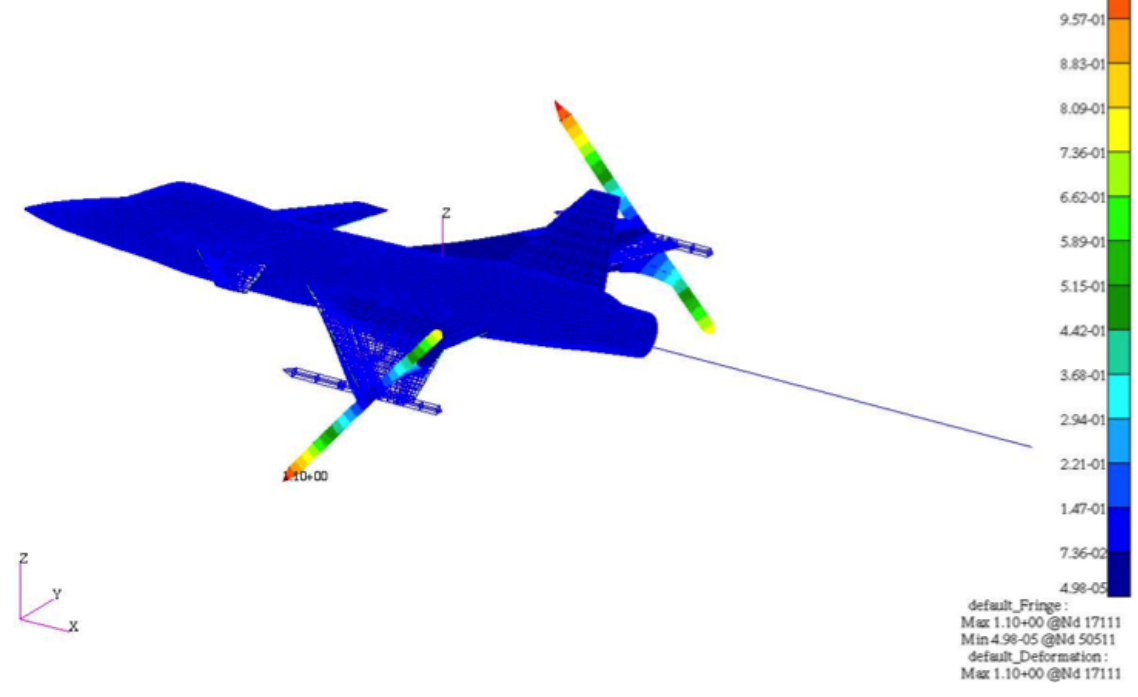

Figure 9. Flexible seventh mode for third configuration.

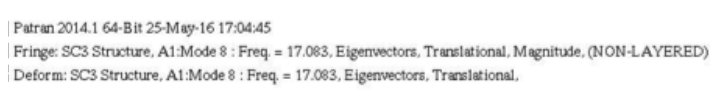

Fringe: SC3 Structure, A1:Mode $8:$ Freq $=17.083$, Eigenvectors, Transiational, Meform:
Defor Structure, A1:Mode $8:$ Freq $=17.083$, Eigenvectors, Translational.

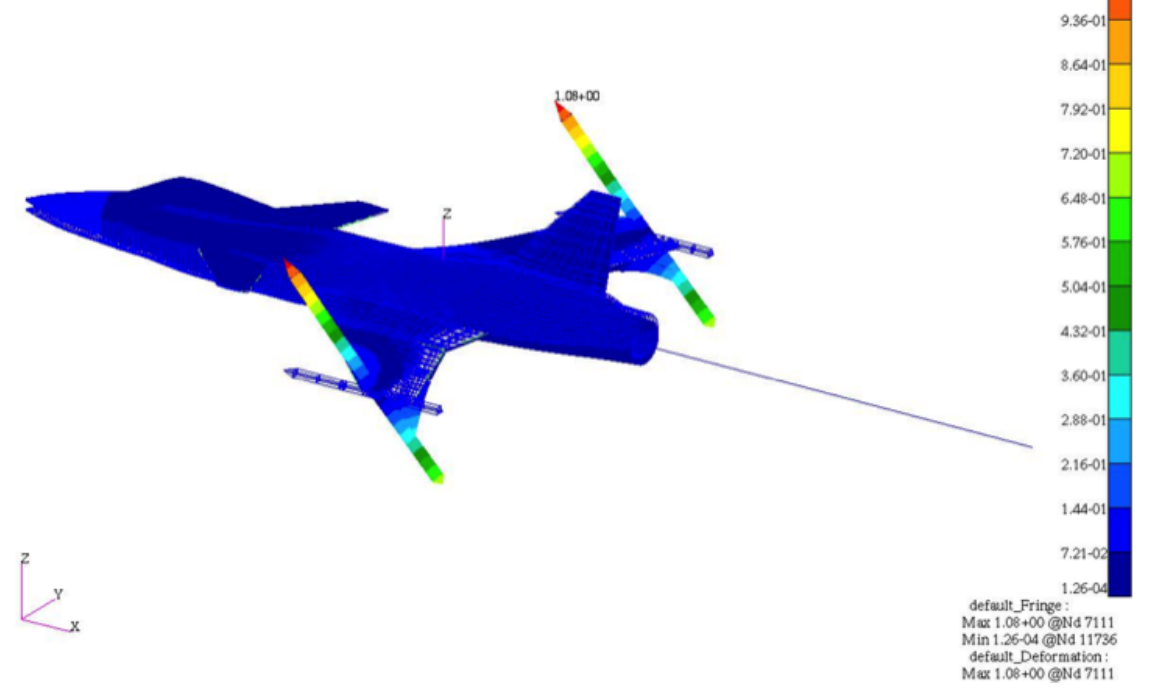

Figure 10. Flexible eighth mode for third configuration.

Linear flutter analyses were performed and are presented as V-g-f plots for the second and third configurations. Figure 11 presents the V-g-f plots for the second configuration, indicating that flutter is far removed from the test envelope. Figure 12, however, indicates a significant reduction in the flutter condition with the added masses in the tip stores. 

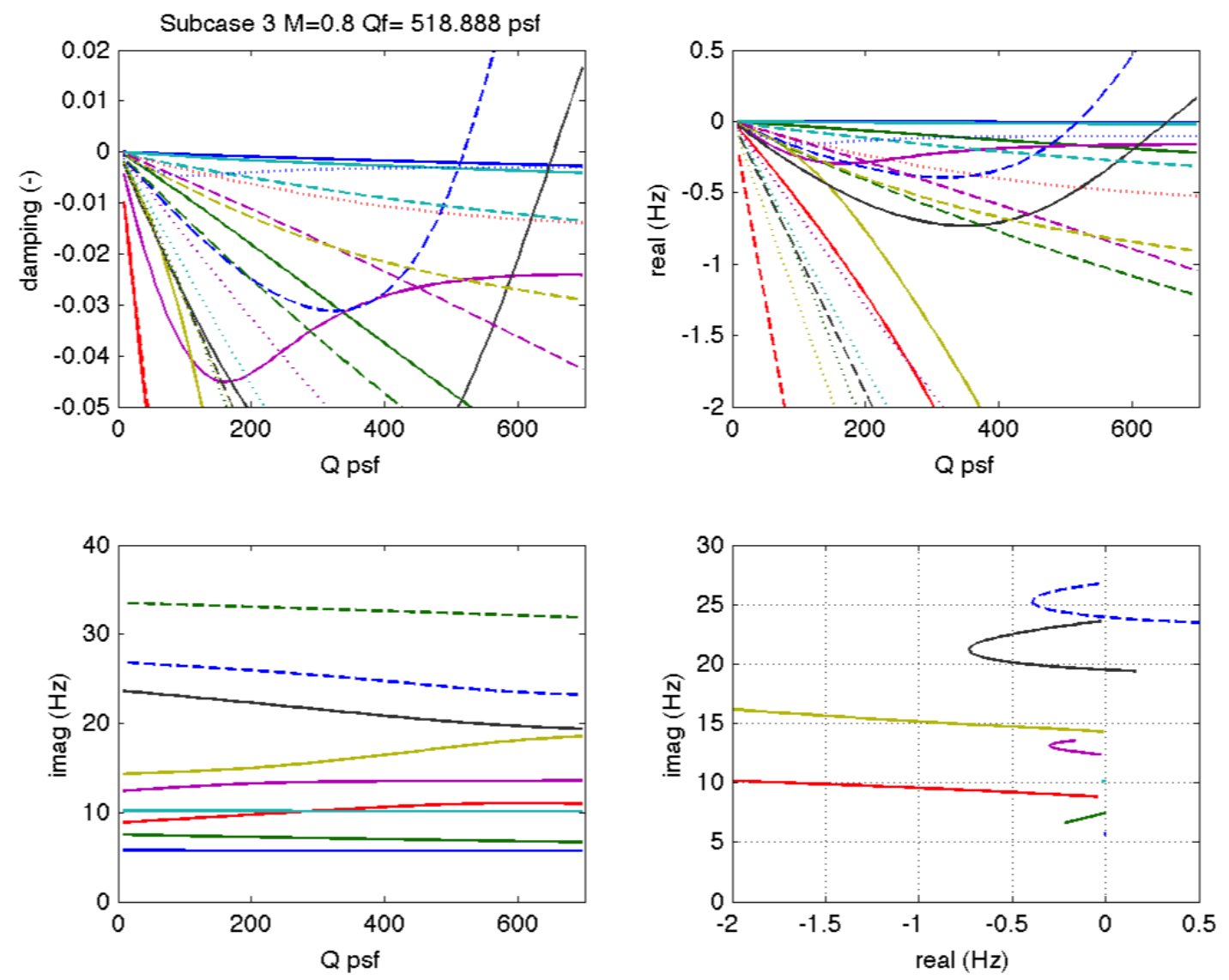

Figure 11. V-g-f plots for the second configuration at $M=0.80$. 

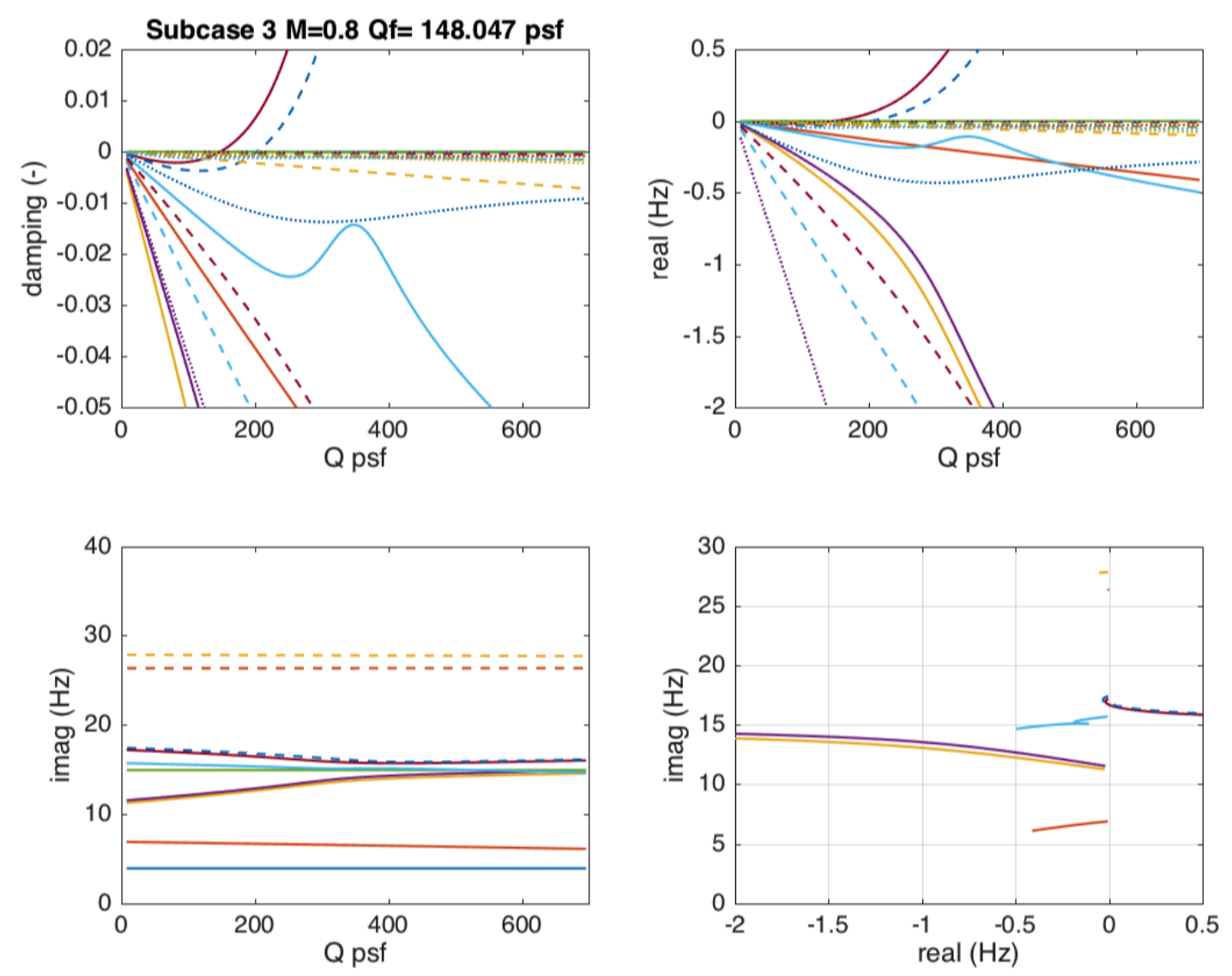

Figure 12. V-g-f plots for the third configuration at $M=0.80$.

The analytical flutter predictions for the second and third configurations, based on linear aeroelastic analyses, are presented in Figure 13. As can be seen in Figure 13, the analytical flutter boundaries for the second configuration (without tip ballast) occur at very high dynamic pressures, outside of the TDT test envelope in some cases, and, therefore, flutter is not a significant concern for this configuration (nor the first configuration). The analytical flutter boundaries for the third configuration (with tip ballast) are also presented in Figure 13. For this configuration, the predicted flutter boundaries are mostly within the TDT test envelope. In fact, during the last phase (flutter) of the test, three separate flutter events were encountered at $\mathrm{M}=0.90$ and around a dynamic pressure of $130 \mathrm{psf}$; lower than the boundary predicted by linear aeroelastic analysis. Therefore, this is indicative of a nonlinear flutter incident, possibly induced by transonic aerodynamics. CFD-based analyses, required to analyze this flight regime, are discussed in the next section. 


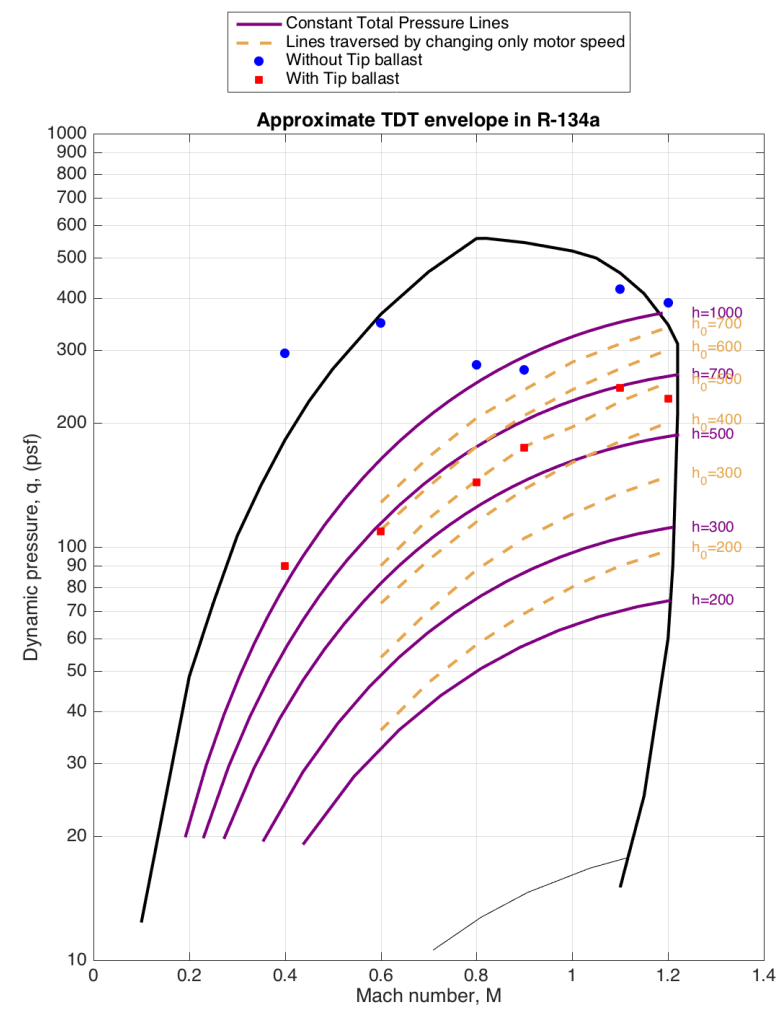

Figure 13. Flutter predictions of the KTH-NASA aeroelastic wind-tunnel model for second and third configurations.

\section{V.B. CFD-Based Analyses}

Unstructured CFD grids have been generated at KTH for use with Reynolds-Averaged Navier-Stokes (RANS) codes. These grids include the wind-tunnel model configuration with and without the canards in order to determine the effect of the canards in preliminary analyses. Inviscid, steady, rigid solutions have been computed by the KTH group at several test conditions in order to determine the aerodynamic loads at those conditions.

Using the unstructured grid generated at KTH, NASA has generated viscous, steady, rigid solutions at $\mathrm{M}=0.7$ and 0 degrees angle of attack for the configuration with canards. Presented in Figure 14 is an image of the pressure distributions at this condition using the NASA-Langley-developed FUN3D RANS CFD code.

Using the viscous grid, preliminary analyses have been performed to compare computational results to experimental data. Presented in Figure 15 is a diagram of the spanwise locations of the pressure transducers installed in the KTH wind-tunnel model. Figure 16 shows the chordwise distribution and location of the pressure taps.

A comparison of computational and experimental pressures at $\mathrm{M}=0.70$ and 0 degrees angle of attack for the Group 1 set of pressure taps is presented as Figure 17. At this outboard span station, there are noticeable differences, probably due to the static aeroelastic deformation that is not included in the current FUN3D computations. Results presented also include preliminary analyses that include the effect of a FUN3D model of the TDT test section. At this location, there appears to be some effect of the tunnel environment on the pressure distribution.

A comparison of computational and experimental pressures at $\mathrm{M}=0.70$ and 0 degrees angle of attack for the Group 2 set of pressure taps is presented as Figure 18. At this inboard span station, there are less differences, probably due to the reduced static aeroelastic deformation. Additional analyses are underway that include the effect of aeroelastic deformation as well as flutter predictions at transonic Mach numbers. The results that include the effect of the TDT test section appear to be moving away from the experimental 


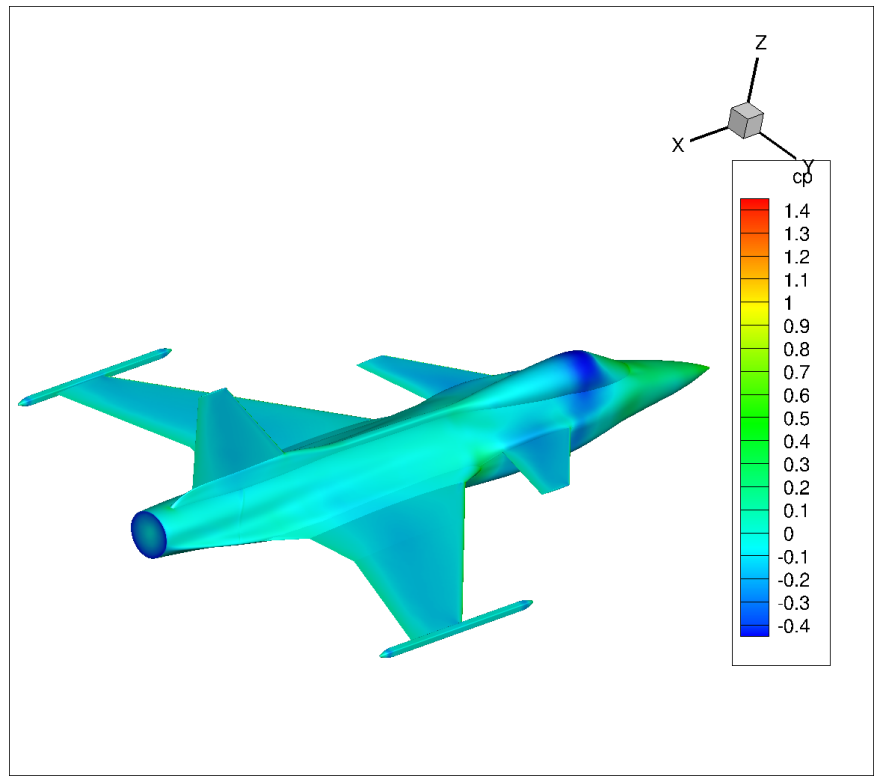

Figure 14. Pressure distributions at $\mathrm{M}=0.7, \mathrm{AoA}=0$ degrees using $\mathrm{FUN3D}$ code.

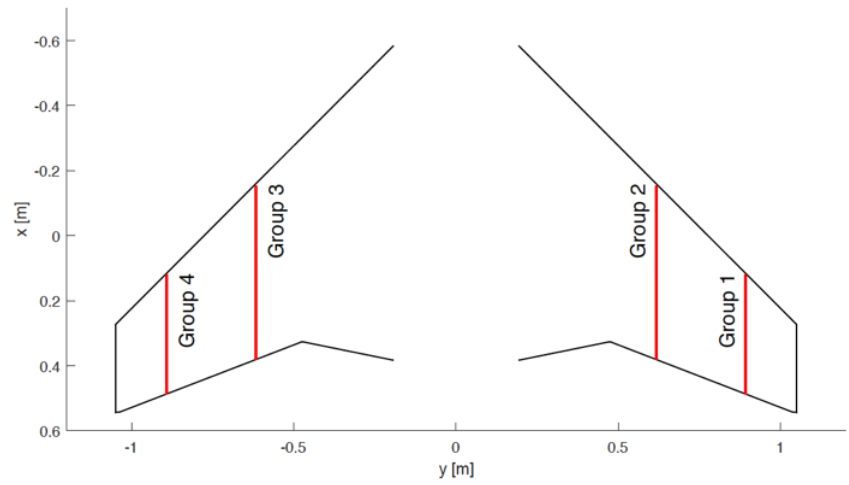

Figure 15. Spanwise locations of pressure taps for KTH wind-tunnel model.

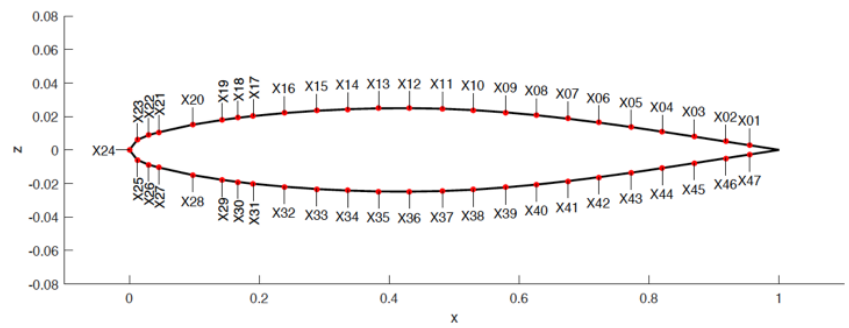

Figure 16. Chordwise locations of pressure taps for KTH wind-tunnel model. 


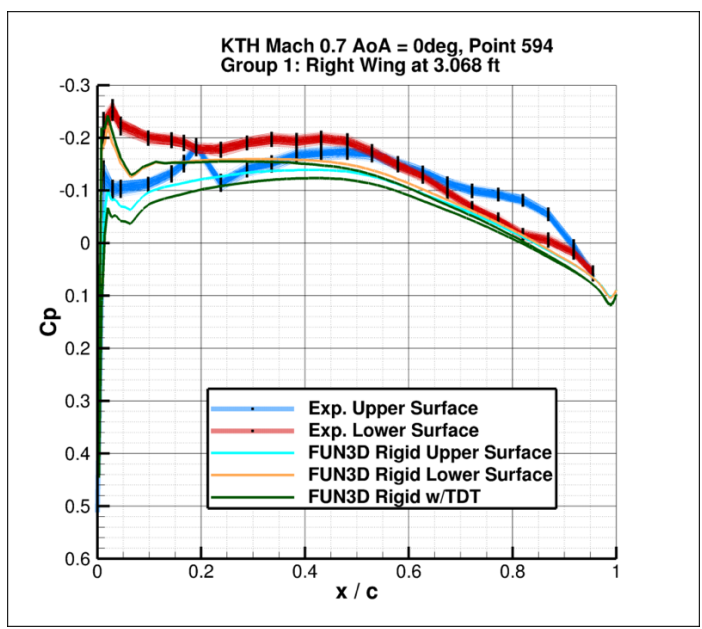

Figure 17. Comparison of computational and experimental pressure distributions at $\mathrm{M}=0.7$, AoA $=0$ degrees for $\mathrm{Group}$ 1 pressure tap station.

data. Additional analyses are currently underway, including analyses to include the effect of static aeroelastic deformation.

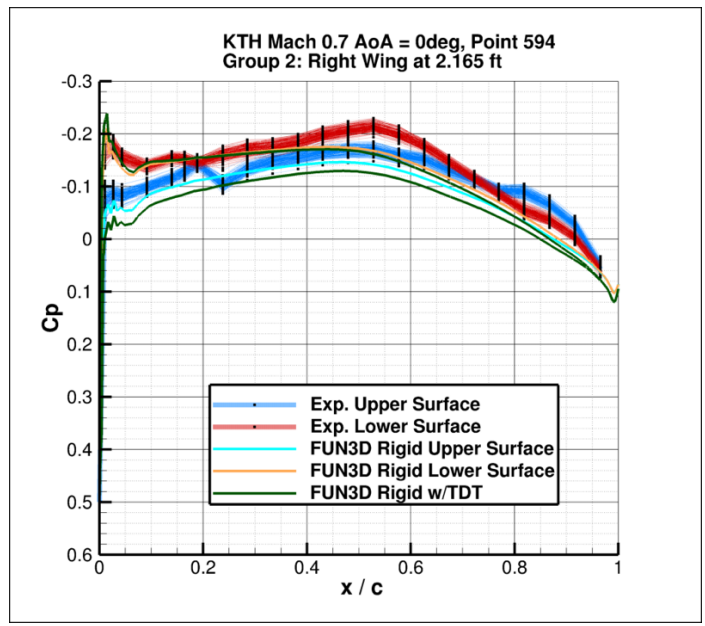

Figure 18. Comparison of computational and experimental pressure distributions at $\mathrm{M}=0.7$, AoA $=0$ degrees for $\mathrm{Group}$ 2 pressure tap station.

\section{V.C. Reduced-Order Models}

The goal behind the development of an aeroelastic ROM for the rapid computation of unsteady aerodynamic and aeroelastic responses is aimed at addressing two challenges. The first challenge is the computational cost associated with full CFD aeroelastic simulations, which increases with the fidelity of the nonlinear aerodynamic equations to be solved as well as the complexity of the configuration. Computational cost, however, may be reduced via the implementation of parallel processing techniques, advanced algorithms, and improved computer hardware processing speeds.

The second, more serious, challenge is that the information generated by these simulations cannot be used effectively within a preliminary design environment. Because the output of these full CFD aeroelastic simulations, such as the responses of the generalized coordinates, is not easily incorporated within a design environment, parametric variations and design studies can only be performed by trial-and-error. As a result, the integration of computational aeroelastic simulations into preliminary design activities involving disciplines such as aeroelasticity, aeroservoelasticity (ASE), and optimization continues to be a costly and 
impractical venture.

However, with the development of reduced-order modeling (ROM) methods, ${ }^{19}$ the rapid generation of root locus plots using CFD-based unsteady aerodynamics is now available to aeroelasticians. This recently developed technology is being applied to the KTH wind-tunnel model for evaluation of aeroelastic mechanisms across several Mach numbers.

An aeroelastic ROM has been developed at a Mach number of 0.7 and 0 degrees angle of attack for the first ten flexible modes. Presented in the following figures are the various results that are used to generate and determine the quality of a particular ROM as it is being developed. This entire process, from reading in the FUN3D ROM output to creating the final root locus plot, takes about a minute.

Figure 19 is the third of ten Walsh functions that are input (simultaneously) into FUN3D in order to generate the output required by the system identification process. Figure 20 presents the generalized aerodynamic force (GAF) output in the third mode due to all ten Walsh functions.

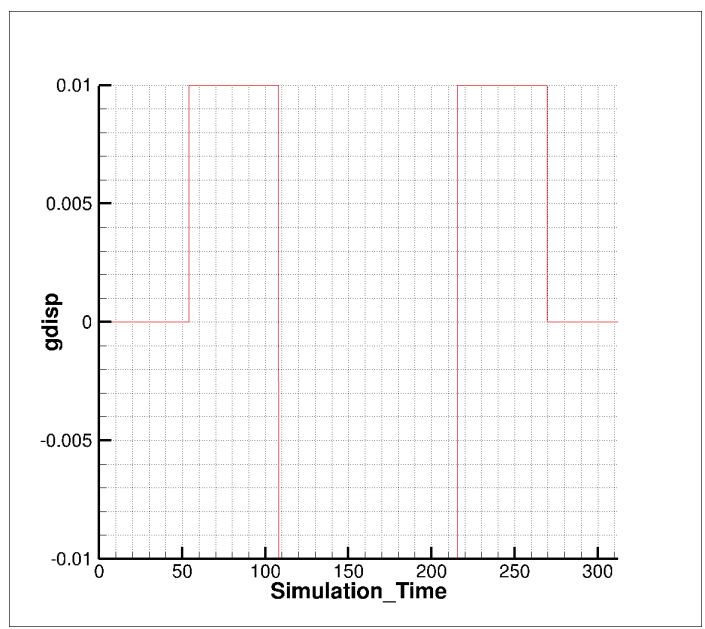

Figure 19. One of the ten Walsh functions used as input to the FUN3D code to generate the response required for ROM creation.

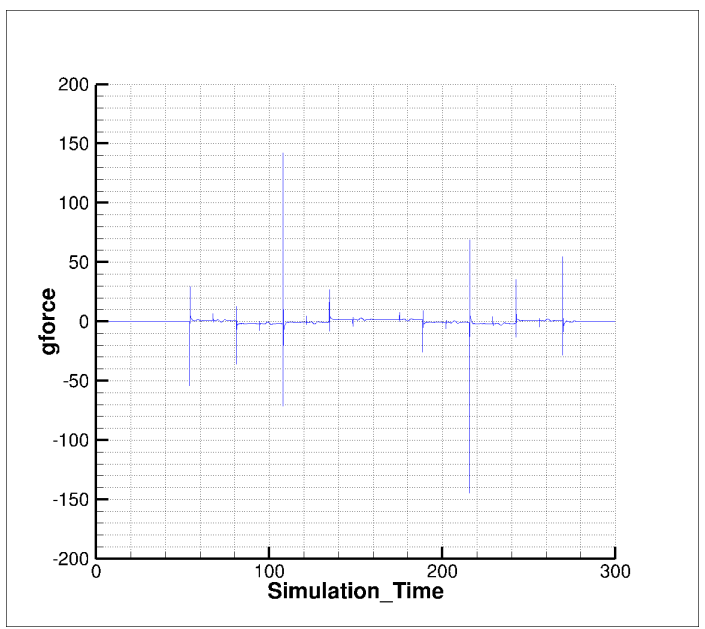

Figure 20. Generalized aerodynamic force for the third mode due to all ten Walsh funtions.

Figure 21 presents the extracted pulse response for the second mode due to the first Walsh function in both the time and frequency domains. For this application, there are ten input modes and ten output GAFs resulting in 100 pulse responses. The first pulse response is the response in the first mode due to the first Walsh function, the second pulse response is the response in the second mode due to the first Walsh function, and so on. This is an important part of the quality control process to make sure that the pulse response is well behaved and has a good bandwidth. Figure 22 presents the singular values and the magnitude of 
the roots that is central to the creation of a good-quality state-space unsteady aerodynamic model. These parameters can be used to determine the level of error retained for a given number of retained states. For most applications and for maximum accuracy, all states are retained.
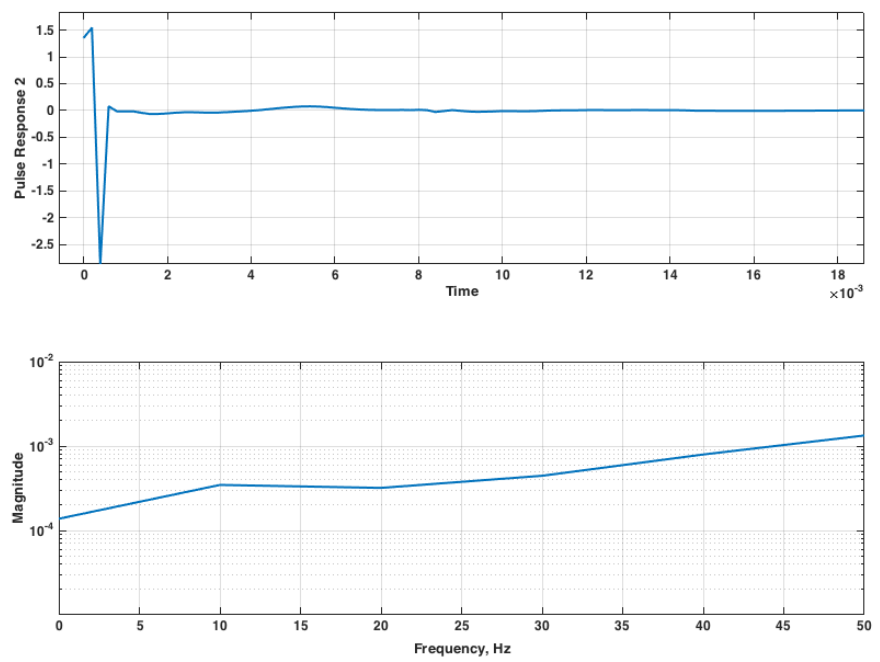

Figure 21. The extracted pulse response for the third mode due to the first Walsh function in time and frequency domains.
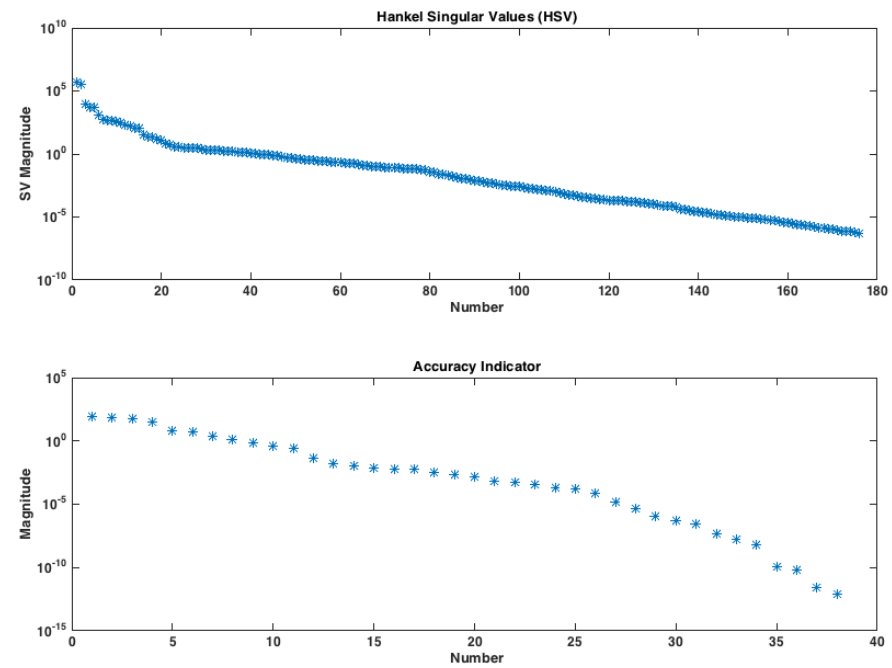

Figure 22. Singular values and magnitude of the roots associated with creation of the unsteady aerodynamic state-space model.

In order to determine the stability and quality of the resultant unsteady aerodynamic state-space model, a z-plane plot of the root of the discrete-time state-space system is generated and presented as Figure 23. As can be seen, this is a stable realization given that all the roots are inside of the unit circle in the z-plane.

Presented in Figure 24 is a comparison of the GAF responses in the third mode due to the ten Walsh functions for the newly-generated ROM (unsteady aerodynamic state-space model) and the results obtained directly from FUN3D. As can be seen, the comparison is excellent, indicating that this is a good-quality ROM. Figure 25 shows the computed errors (mean and maximum percent) between the ROM response and the FUN3D response in GAFs. The errors indicated are per mode and indicate errors on the order of $0.5 \%$ for the worst-case result. The errors are also presented in the frequency domain (Figure 26) in order to 


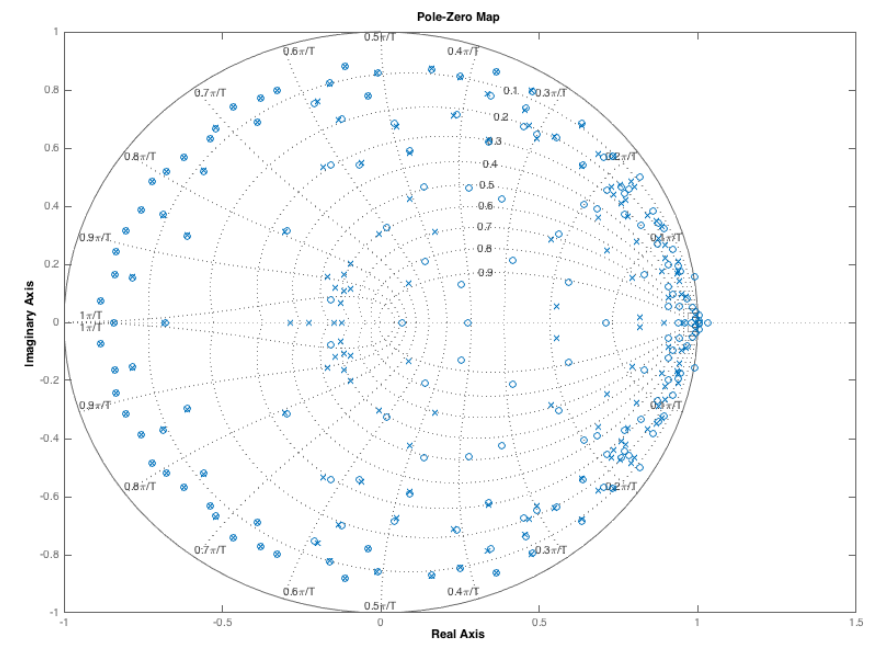

Figure 23. Z-plane plot of the roots of the discrete-time unsteady aerodynamic state-space model.

better understand the frequency content that is being captured by the identified system.

Once the unsteady aerodynamic state-space model is generated and validated, it is combined with a structural state-space model that represents the structural dynamics of the configuration. These two systems are then combined into one aeroelastic system. This then enables the creation of root locus plots in various formats.

A major benefit of this ROM technology is the ability to rapidly generate an aeroelastic root locus plot that reveals the aeroelastic mechanisms occurring at that flight condition. Presented in Figure 27 is the aeroelastic root locus plot at $\mathrm{M}=0.70$ with a variation in dynamic pressure from 20 to $400 \mathrm{psf}$, with the arrows indicating increasing dynamic pressure. Clearly, given that all the roots stay in the left-half plane, there are no modal coalescences, and, therefore, no flutter at this Mach number for this configuration. Additional analyses are underway to compute additional aeroelastic root locus at several Mach numbers for the three different wind-tunnel model configurations.

The computational cost of generating an aeroelastic ROM solution, for this configuration, consisted of one full FUN3D solution that is then used to generate the ROM at that Mach number. This FUN3D solution for generating the aeroelastic ROM ran for about three hours and consisted of 2900 time steps. Once this solution is available, a ROM can be generated within a couple of minutes and then used to generate all the aeroelastic responses at all dynamic pressures. In comparison, a full FUN3D analysis at each dynamic pressure requires two FUN3D solutions: a static aeroelastic solution (10 hours) and a dynamic aeroelastic solution (18 hours). Therefore, a complete set of FUN3D solutions for 20 dynamic pressures would require 560 hours of compute time.

In the root locus plot, each symbol represents the aeroelastic roots at a specific dynamic pressure. It is important to mention that this ROM-based root locus plot is generated in seconds while multiple full FUN3D solutions would be required for each dynamic pressure of interest to generate an equivalent full FUN3D solution root locus.

\section{Concluding Remarks}

Computational results for the KTH-NASA wind-tunnel model were presented. These results included FEM analyses, linear aeroelastic analysis, and CFD-based analyses including ROM solutions. Results indicate that the aeroelastic response of the three different configurations tested are quite different, as expected and as designed. Linear aeroelastic analyses are consistent with wind-tunnel data that revealed no flutter incidents for the first and second configurations (different store configurations) while revealing an increased sensitivity to flutter for the third configuration (added masses in tip stores). Viscous grids have been gen- 


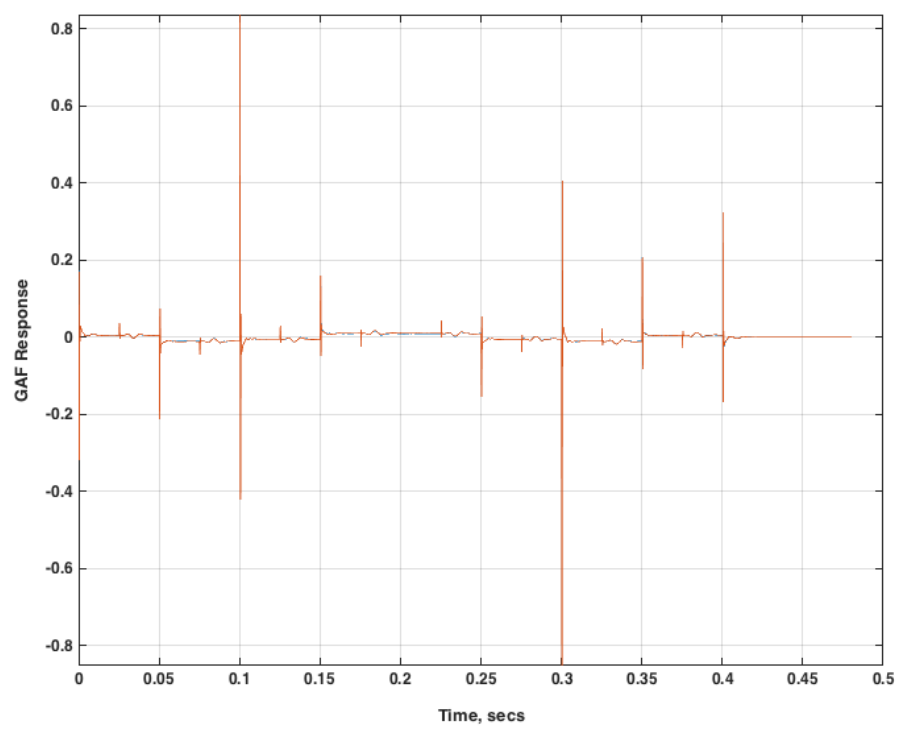

Figure 24. Comparison of the GAF response in the third mode due to all the Walsh functions for the ROM and for the full FUN3D solution.
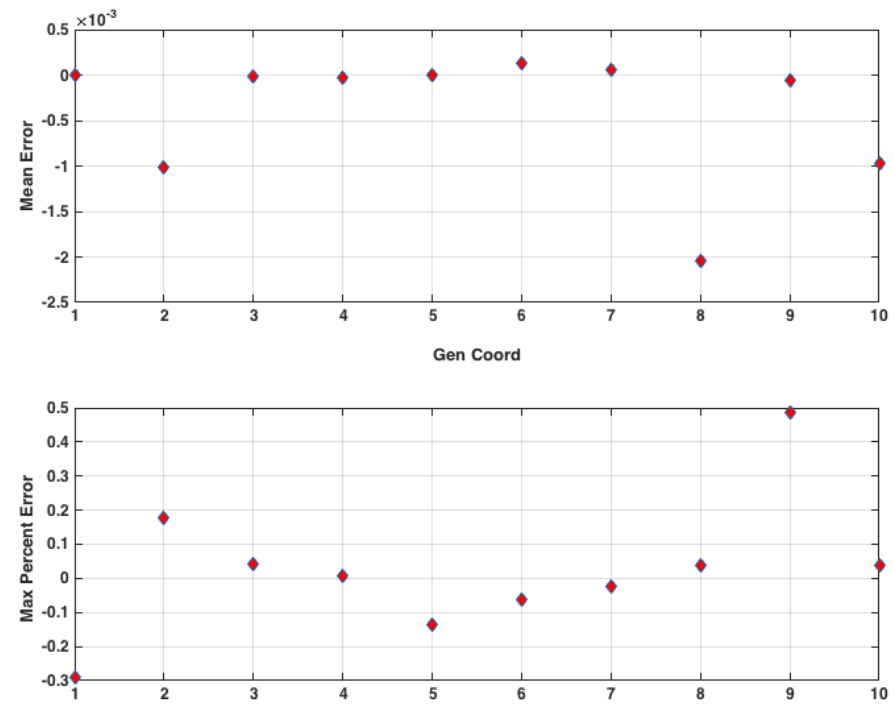

Figure 25. Mean and maximum percent errors per mode for the ROM and the full FUN3D solution. 

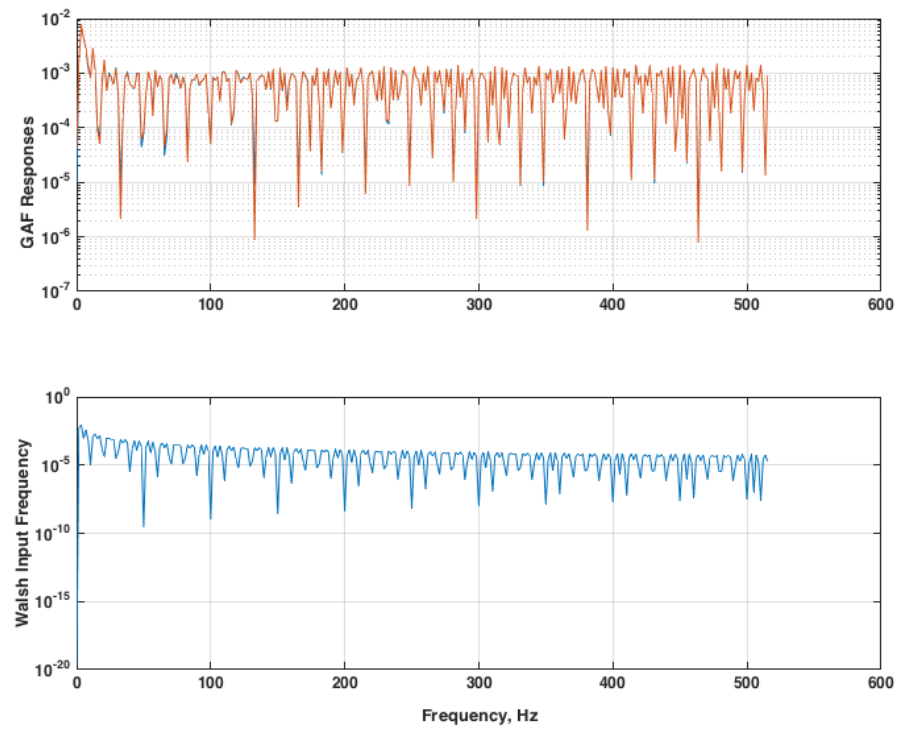

Figure 26. Frequency-domain errors for the third GAF and the frequency content of the Walsh input function.

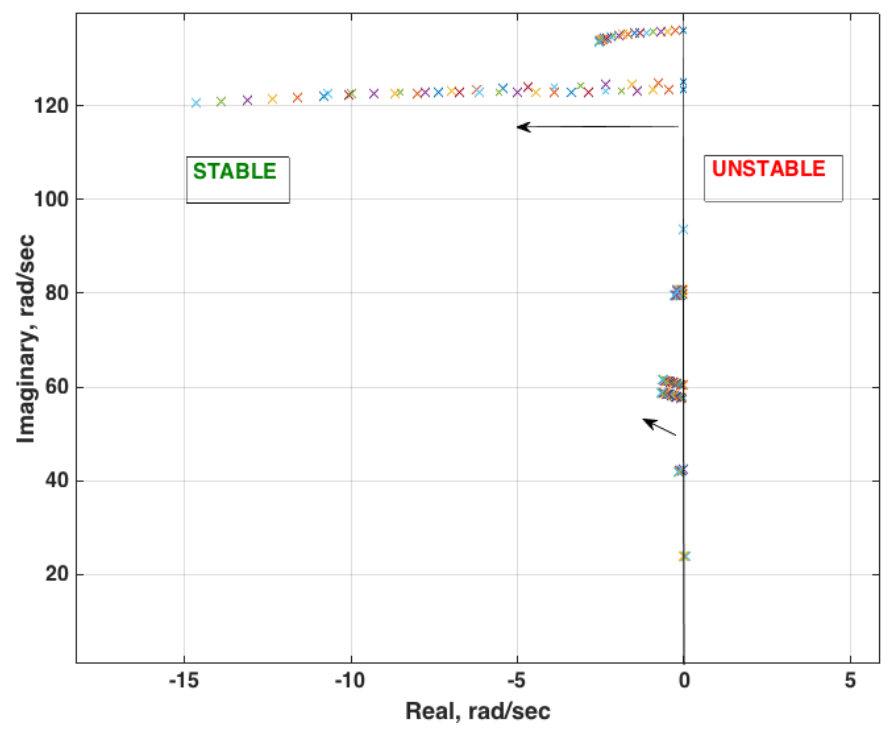

Figure 27. Root locus plot generated from ROM model indicating stable aeroelastic behavior across all dynamic pressures at $\mathrm{M}=0.70$ for the second configuration.

18 of 19 
erated and were used to compute preliminary steady, rigid solutions for comparison with the experimental pressure data. Finally, the process for the creation of an aeroelastic ROM at $\mathrm{M}=0.70$ was detailed resulting in an aeroelastic root locus plot indicating no flutter coalescence up to very high dynamic pressures. Additional analyses are underway to further define the flutter boundary computationally for comparison with experiment.

\section{References}

${ }^{1}$ Patil, M., "Limit-Cycle Oscillations of Aircraft Caused by Flutter-Induced Drag," AIAA Journal of Aircraft, Vol. 41, May 2004, pp. 571-576.

${ }^{2}$ Gopinath, A., Beran, P., and Jameson, A., "Comparative Analysis of Computational Methods for Limit-Cycle Oscillations," 47th AIAA/ASME/ASCE/AHS/ASC Structures, Structural Dynamics, and Materials Conference, April 2006.

${ }^{3}$ Gordnier, R. E., "Computation of Limit-Cycle Oscillations of a Delta Wing," AIAA Journal of Aircraft, Vol. 40, Nov. 2003, pp. 1206-1208.

${ }^{4}$ Denegri, C. M., Dubben, J. A., and Maxwell, D. L., "In-Flight Wing Deformation Characteristics During Limit Cycle Oscillations," AIAA Journal of Aircraft, Vol. 42, March 2005, pp. 500-508.

${ }^{5}$ Padmanabhan, M. A., Pasiliao, C. L., and Dowell, E. H., "Simulation of Aeroelastic Limit-Cycle Oscillations of Aircraft Wings with Stores," AIAA Journal, Vol. 52, Oct. 2014, pp. 2291-2299.

${ }^{6}$ Bunton, R. W. and Denegri, C. M., "Limit Cycle Oscillation Characteristics of Fighter Aircraft," AIAA Journal of Aircraft, Vol. 37, Sept. 2000, pp. 916-918.

${ }^{7}$ Yao, W. and Marques, S., "Prediction of Transonic Limit-Cycle Oscillations Using an Aeroelastic Harmonic Balance Method," AIAA Journal, April 2015.

${ }^{8}$ Sheta, E. F., Harrand, V. J., Thompson, D. E., and Strganac, T. W., "Computational and Experimental Investigation of Limit Cycle Oscillations of Nonlinear Aeroelastic Systems," AIAA Journal of Aircraft, Vol. 39, Jan. 2002, pp. $133-141$.

${ }^{9}$ Bendiksen, O., "Transonic Limit Cycle Flutter/LCO," 45th AIAA/ASME/ASCE/AHS/ASC Structures, Structural Dynamics and Materials Conference, April 2004.

${ }^{10}$ Silva, W., Brenner, M., Cooper, J., Denegri, C., Dunn, S., Huttsell, L., Kaynes, I., Lind, R., Poirel, D., and Yurkovich, R., "Advanced Flutter and LCO Prediction Tools for Flight Test Risk and Cost Reduction - An International Collaborative Program for T\&E Support," 2005 U.S. Air Force TEE Days, Dec. 2005.

${ }^{11}$ Chabalko, C., Hajj, M., Mook, D., and Silva, W., "Characterization of the LCO Response Behaviors of the NATA model," 47th AIAA/ASME/ASCE/AHS/ASC Structures, Structural Dynamics, and Materials Conference, April 2006.

${ }^{12}$ Silva, W. and Dunn, S., "Higher-Order Spectral Analysis of F-18 Flight Flutter Data," 46th AIAA/ASME/ASCE/AHS/ASC Structures, Structural Dynamics and Materials Conference, April 2005.

${ }^{13}$ Silva, W. A., Ringertz, U., Stenfelt, G., Eller, D., Keller, D. F., and Chwalowski, P., "Status of the KTH-NASA WindTunnel Test for Acquisition of Transonic Nonlinear Aeroelastic Data," 15th Dynamics Specialists Conference, AIAA SciTech Forum, No. AIAA 2016-2050, Jan. 2016.

${ }^{14}$ Corliss, J. M. and Cole, S. R., "Heavy Gas Conversion of the NASA Langley Transonic Dynamics Tunnel," Proceedings of the 20th Advanced Measurements and Ground Testing Technology Conference, No. 98-2710, Albuquerque, NM, June 1998.

${ }^{15}$ Cole, S. R. and Rivera Jr, J. A., "The New Heavy Gas Testing Capability in the NASA Langley Transonic Dynamics Tunnel," Royal Aeronautical Society Wind Tunnels and Wind Tunnel Test Techniques Forum, No. No. 4, Cambridge, UK, April 1997.

${ }^{16}$ Siemens Product Lifecycle Management Software Inc., NX Nastran 8 Quick Reference Guide, 2011.

${ }^{17}$ Passalacqua, F., "Characterization of glass fiber reinforced material through off-axis tensile tests," Tech. rep., Department of Aeronautical and Vehicle Engineering, 2014.

${ }^{18}$ Qualisys AB, Oqus - Qualisys motion capture camera with high-speed video, Product Information 100, 300 and 500 series, 2011.

${ }^{19}$ Silva, W. A., "Simultaneous Excitation of Multiple-Input/Multiple-Output CFD-Based Unsteady Aerodynamic Systems," Journal of Aircraft, Vol. 45, No. 4, July-August 2008, pp. 1267-1274. 